\title{
TOWARDS SUSTAINING PERFORMANCE IN A GAUTENG SECONDARY SCHOOL
}

\section{Authors:}

Nonceba P. Ntuta ${ }^{1}$

Willem J. Schurink ${ }^{2}$

\section{Affiliations:}

${ }^{1}$ Department of Industrial

Psychology and People

Management, University of

Johannesburg, South Africa

${ }^{2}$ Department of Human

Resources Management,

University of Johannesburg,

South Africa

Correspondence to:

Willem Schurink

email:

wjs@webafrica.org.za

Postal address:

Department of Industrial

Psychology and People

Management, University of

Johannesburg, PO Box 524 ,

Auckland Park 2006,

South Africa

\section{Keywords:}

politically-driven

reform; education; poor

school performance;

school improvement;

transformation

\section{Dates:}

Received: 17 Feb. 2009

Accepted: 21 Sept. 2010

Published: 26 Nov. 2010

How to cite this article:

Ntuta, N.P., \& Schurink, W.J.

(2010). Towards sustaining performance in a Gauteng secondary school. $S A$

Journal of Human Resource

Management/SA Tydskrif vir

Menslikehulpbronbestuur,

8(1), Art. \#191, 9 pages. DOI:

10.4102/sajhrm.v8i1.191

\section{This article is available} at:

http://www.sajhrm.co.za

(C) 2010. The Authors.

Licensee: OpenJournals

Publishing. This work

is licensed under the

Creative Commons

Attribution License.
ABSTRACT

Orientation: Poor school performance is a major problem in South Africa. To date the success of intervention strategies that were aimed at turning the situation around in dysfunctional schools have been short lived and were not sustainable.

Research purpose: The aim of this study was to determine the reasons for the failure of an intervention programme in a school that managed to perform well for the time when it received assistance.

Motivation: It is essential to determine the reasons for this continuous failure of school intervention programmes if we want to address the serious problems experienced by the South African education system.

Research design, approach and method: In this study, a qualitative research approach within a case-study design was used.

Main findings: The main reasons for the inability of the school to sustain its performance were not internal (within the school itself) but external (within the education system).

Practical and managerial implications: The findings of this study highlight the importance of external leadership and support by the districts and the Department of Education in changing the poor performance of schools at large.

Main contribution: Contrary to literature emphasising the lack of leadership at school level as the main problem of poor school performance, this study found that the problem was mainly due to a lack of leadership at departmental level.

\section{INTRODUCTION}

During the first five years of democracy, the South African parliament had the massive task of debating and passing very important legislation that laid the basis for transformation in the education system. Notably these included the National Education Policy Act of 1996 and the South African Schools Act of 1996, which, for the first time, created a framework for a single public-school system in the country.

However, this transformation process and the policies that were put in place could not solve the more intricate problems of the education system. Little and Houston (2003) are of the same opinion when they argue that politically-driven school reform goes hand in hand with reform driven by the individual teacher and the school. They emphasise that unless efforts are directed squarely towards reform within the classroom, improvement in student outcomes will not occur. This was clearly reflected by the poor Senior Certificate results achieved during the period of 1994-1999.

Attempting to redirect and stabilise an unstable education system the former Minister of Education, Professor Kader Asmal, announced a number of programmes to address the legacy of racist administration spanning over a hundred years which left many schools on the brink of collapse. This was particularly true for secondary schools in urban areas. Whilst various policies were put in place, implementing them proved to be problematic, hence the introduction of a number of intervention programmes at provincial and national level.

Following this, Ignatius Jacobs, then Member of the Executive Council (MEC) for education in Gauteng, introduced an intervention programme referred to as the Education Action Zones (EAZ). This programme was directed at 71 secondary schools in Gauteng that had a pass rate of less than $20 \%$ in their Senior Certificate results at the end of 1999. The programme was designed to ensure direct and intensive support and capacity building to these schools by dedicated teams for a period of three years. The innovation was aimed at the following:

- implementing special programmes for learners, for example, the training of learner leadership and conducting motivational talks for learners, in particular for Grade 12s

- monitoring progress in the implementation of the official school syllabus

- providing additional training for teachers in high-risk subjects such as Mathematics, Physical Science, Accounting and English

- providing additional training to school management teams and school governing bodies such as curriculum management, their roles and responsibilities and conflict management

- establishing special business partnerships with other countries, eg with France to access extra resources, such as exchange programmes that are aimed at developing the management skills of principals, educators and school-governing bodies

- entering into a partnership with the religious fraternities to provide after-school programmes

- reaching special security agreements with the South African Police Services (SAPS).

Therefore the EAZ Programme was aimed at stabilising the school environment by controlling and structuring schools identified to be at risk. Some scholars (Fleisch, 2006) suggested that such troubled 
schools required the State to be more authoritative in its demands for change and enforcement of regulations. By implementing the EAZ Programme the government has taken firm control of the situation.

According to Fleisch (2006), the EAZ Programme in Gauteng province, South Africa, has been widely seen as a very successful school improvement initiative. This is of particular significance because it represents a unique model of top-down, bureaucratic accountability as a vehicle for turning around dysfunctional secondary schools. Unfortunately at the end of 2004, when most EAZ fieldworkers were withdrawn from the schools, a number of schools, after having graduated successfully from the EAZ category, fell back into their old patterns. Once again they achieved a poor Grade 12 pass rate and had a low level of university exemption. Notably eight of these schools obtained a pass rate mark of below $30 \%$, whilst the majority performed below $60 \%$ which is the percentage required to be classified as an underperforming school.

Being an employee of the Education Department as one of the EAZ field workers under the Special Task Sub-directorate, this decline became a cause of great concern to the first author. This was the direct cause for her decision to undertake research to establish the reason why some schools succeeded in sustaining high-performance levels and positive change whilst others failed to do so.

Hence the researcher undertook a qualitative research study whereby her own experiences as an EAZ team member were used as a guideline to explore the feelings of some staff members of a school where the EAZ Programme was implemented. Fleisch (2002) supports the need for undertaking research on schoolimprovement models that are successful. Bipath (2002) in her mini-dissertation echoes Fleisch's statements by recommending further research on transformation strategies for dysfunctional schools.

\section{The broad research question}

The broad research question or aim of this study is formulated as follows: How can the high performance and positive change, which was attained by some of the dysfunctional secondary schools in the Gauteng province between 2001 and 2004 (the period that the Gauteng Department of Education, South Africa administered its EAZ Programme) be sustained?

More specifically, the objectives were to explore the influence of external pressures on school improvement in comparison with internal motivation in sustaining high performance and positive change. These objectives included the development of guidelines that were based on the perceptions of school staff members, who were functioning at grass-roots level, of how educators could be empowered to improve sustainable performance.

\section{RESEARCH DESIGN}

\section{Research approach}

It is imperative for a qualitative researcher to explicitly outline his or her ontology. According to Mason (1996) ontology refers to the researcher's view on the essence and nature of the social world. The ontological view of the researcher needs to be understood in order to position him or her in terms of varying perspectives in this regard. There are three broad ontological perspectives by which the researcher can be positioned. The first of these is characterised by the view of the positivists that there is a reality 'out there' and that it can be studied objectively. Ritchie and Lewis (2003, pp. 11-23) refer to this reality as realism, that is, that 'there is an external reality which exists independently of people's belief and understanding about it'. The second ontological perspective also states that there is a reality 'out there', but this perspective acknowledges that this must be studied through people's perceptions in order to access the richness of these experiences. Ritchie and Lewis (2003, p. 23) refer to this reality as materialism, that is, that 'there is a real world, but only material features of that world hold reality'. The third, more radical, ontological perspective is characterised by the view that reality is constructed jointly when the researcher engages with the subject. Ritchie and Lewis $(2003$, p. 23) refer to this reality as idealism, where 'reality is only knowable through the human mind and socially constructed meanings'.

The second ontological perspective was followed in this study. There is a need to gain an understanding of the richness of people's experiential worlds in order to make sense of the reality out there. The respondents' own interpretation of the research question and their perspectives and feelings in this regard are of critical importance. The aim is to understand their perspectives in the context of their experiences in terms of the EAZ Programme.

In addition to one's ontology, one also needs to determine what one regards as knowledge or evidence of things in the social world and thus how knowledge could best be gained. This represents one's epistemological perspective. According to Mason (1996), epistemology is literally one's theory of knowledge and should therefore concern the principles and rules by which one decides whether and how social phenomena can be known and how knowledge can be demonstrated. Epistemological questions should direct one to a consideration of the philosophical issues that are involved in working out exactly what one would consider as evidence or knowledge of social things. Generally speaking ontological and epistemological perspectives need to be corresponding and therefore the method of creating knowledge has to be in accordance with the particular ontological perspective of the researcher (Mason, 1996). Positivists believe that the methods of the natural sciences are appropriate for social enquiry because human behaviour is governed by lawlike regularities; it is possible to carry out independent, objective and value-free social research. The interpretive tradition, on the other hand, claims that the social world is not governed by lawlike regularities, but that social reality should be understood through the meaning that the subjects give to their experiences. Qualitative research is largely associated with interpretivism (Ritchie \& Lewis, 2003).

\section{Research strategy}

A secondary school involved in the first cycle of the EAZ Programme was chosen for the purpose of this research. The reason for selecting this school was three-fold. Firstly, during the EAZ intervention it sustained and continuously improved its organisational performance, as measured by the Grade 12 examination results. However, since graduating from the programme and the consequent withdrawal of EAZ fieldworkers it showed a steady decline in the pass rates of matriculants. Secondly, it provided a setting, which was rich in data as required by qualitative research and, finally, it suited the researcher logistically as the school was within easy reach of the researcher's home. The first author, as an EAZ fieldworker, also had previous contact with the school; thus making it easier to gain entrance to the research setting.

\section{Research method}

\section{Research setting}

The school under investigation was identified as the research setting for the study. Established in 1978, it started as a junior secondary school and graduated to senior secondary in 1987. The school is situated on the western side of a township, which is a very poor area, made up of informal settlements. Zulu people represent the dominating ethnic group but there are also Southern and Northern Sotho people. This part of the township is regarded as a dangerous section, where learners are mostly over-aged and often are involved in gang related activities, drugs and gambling - even on the school premises. 


\section{Entrée and establishing researcher roles}

Access to the research setting was obtained through the researcher's experiences as an EAZ team member at the school where the programme was implemented. An informed consent form was used to obtain the permission of each research participant to take part in the study. This informed consent form explained the aims of the study and insured the confidentiality of the research participants. Special care was taken by the first author not to let her previous contact and familiarity with the school culture affect her observations at the school. Continuous critical reflection on these observations helped to ensure the quality of the research.

\section{Sampling}

The sample that was drawn from the organisation consisted of the principal and the deputy principal and staff members. The sampling method used can best be described as purposive sampling where access points are identified and informative subjects are selected in such a way that they assist in collecting information that is helpful in answering the research question. Decisions regarding sampling were initially based on the researcher's inside perspective and knowledge of the school. The sampling that followed was more theoretical, as decisions to involve additional sources of data were directed by the understanding of the situation which evolved during the research process.

\section{Data-collection methods}

In seeking to explore the reason why the secondary school failed to sustain its high performance and positive change after the EAZ Programme had been administered to it, a single casestudy design was employed. As an example, a funnel may best represent the general design of the case study. The start of the study was the wide end of the funnel. The design was continually modified and procedures were changed as more was learnt about the topic of study and the investigation became more focused.

Mason (1996) indicates that it is critical that the researcher establish 'links' between research questions, methodologies and methods and states that the researcher needs to be clear on the methodological implications of his or her choices. The researcher thus needs to identify appropriate data sources and methods to support the research question. Unstructured interviews, focus groups and solicited documents such as essays or memoranda and unsolicited documents such as essays were used in this study in an effort to obtain rich data.

Three rounds of interviews were held, two with each research participant and a third with participants in a focus-group situation. Each interview lasted between one and two hours. The main purpose of the first round of interviews was to establish the social and professional backgrounds of research participants and how they came to be employed at the specific school. These interviews also included the performance and the general organisational culture of the school before the intervention programme was administered.

The second round concerned the role played by EAZ Programme and the reasons for the notable continuous decline of the general school functioning that followed, including, but not limited to the Grade 12 final examination results as from 2004 to the date of the study.

During the third and the last round of interviews, the researcher's own views and understanding of the entire process and the problems encountered were presented for discussion to the research participants for feedback. The purpose of these interviews was for the grass-roots practitioners to help develop guidelines of how positive changes and performance in a secondary school could be sustained after an intervention programme had been terminated.
In addition, participant observation, as well as solicited and unsolicited documents, was used to gain insight into the reasons why the school improvement programme failed.

\section{Recording and management of data}

In qualitative research, it is important that the researcher must be able to provide detail descriptions of people, events, objects, activities and conversations. Researchers also need to record all ideas, strategies, reflections and obstacles that emerged during the course of the study. These are recorded by means of audio recording, field notes and project diaries (Schwandt, 2007).

\section{Data analysis}

Data analysis involves working with data, organising it, breaking it into manageable units, synthesising it, searching for patterns, discovering what is important and what is to be learned and deciding what to tell others. In short, qualitative data analysis is a process of inductive reasoning, thinking and theorising. The aim of analysis and interpretation in qualitative research, as in social-science research generally, is to attempt to gain insight and understanding into the phenomena under study. This is achieved through the systematic ordering and reordering of the data, that is, by continually trying to classify and categorise the data according to the similarities and dissimilarities found, as well as looking for underlying patterns and even universals.

Schurink's (2004) general guidelines were followed by being attentive to words and phrases in the interviewees' own vocabularies that captured the meaning of what they did or said. As Babbie (1983) suggests, various themes were developed and compared with each other to find underlying similarities between them. These methods of analysis are not as formal as the grounded-theory approach or as analytical induction. More specifically:

- the findings and insights were scrutinised by reading and re-reading the data

- overarching themes were identified that led to nonsustainability of performance and change of the school after an intervention programme had been withdrawn

- an analysis was undertaken of the perceptions of educators at grass-roots level to outline guidelines towards sustaining performance.

In qualitative research, interpretation must be seen as a process that entails the entire study (Maxwell, 2005). As the data were collected, the researcher simultaneously tried to make sense of, or interpret, the views and experiences that the research participants shared during the interviewing process, as well as of her own views and thoughts during these discussions and whilst listening to audio tapes afterwards. These reflections were outlined by compiling field notes where the data were linked with some relevant literature.

The next step was the undertaking of intensive data analysis. More specifically the findings and insights were scrutinised and three overarching themes were identified that led to nonsustainability of performance and change of programmes implemented by the school under study after an intervention programme had been withdrawn. From this process, guidelines were developed towards sustaining performance as influenced by perceptions of educators at grass-roots level.

\section{Strategies used to ensure quality data}

Care was taken not simply to deal with the data management by merely recording the data. As Marshall and Rossman point out,

... the researcher's transcription, done with the literature review, previous data, and earlier analytical memos in mind, can become a useful part of data analysis and not a mere clerical duty.

(Marshall and Rossman, 1995, pp. 110-111)

Care was thus taken to undertake a first round of analysis of the data whilst transcribing the tapes and writing field notes. The 
efficiency of data analysis was greatly increased by combining data, recording it and doing its preliminary analysis. Continuous critical reflection and recording of the implications of the data brought awareness of the inter-subjective dynamics between the researcher and the research conducted.

\section{Reporting style}

A modernistic qualitative research reporting style was used for this research where the author related the story about circumstances surrounding the school's performance through the words of the research participants.

\section{FINDINGS}

The school profile, which is an official document indicating the basic school information, revealed certain findings.

The pattern of learner enrollment since 2000 up to 2007 was as follows:

From Table 1 it is clear that the enrollment during the 2000-2001 period was very high, but it dropped during the 2002-2003 period (although in 2003 it again began to escalate) when the EAZ Programme was operating there. Since 2005 up to 2007 the figures were back to what they were in 2000. The Grade 12 results from 1994 up to 2006 showed the following pattern:

Table 2 indicates that the school was never strong academically, but improved drastically in 2002 when EAZ Programme was fully implemented. It showed a steady decline since 2004, when most EAZ fieldworkers were removed from the schools. According to the history of the school (as noted in the school profile) and from my own observation and experience during the execution of the EAZ Programme, the school battled with the following problems:

- inadequate school funds

- teenage problems where girl learners became pregnant and attended school irregularly

- educators not sufficiently trained in new National Curriculum syllabus
- corporal punishment was abolished and alternatives given by the department were not effective

- over-enrollment of learners

- limited resources - over-enrollment exerting high pressure.

These problems were unfortunately not being dealt with during the implementation of the EAZ Programme. In fact the school managed to improve performance despite these problems. After the EAZ Programme was discontinued teachers still had to face them head on

\section{Background to the problem}

Apart from these problems, the research participants felt that the problems were escalated by the lack of performance by the first permanent principal. He was said to be too kind and soft-hearted, although he was a positive motivator who acknowledged good work where due and always made excuses for the poor performance of educators. He was not able to provide proper direction and guidance to educators or learners. As one participant put it: '.. as the SMT we were powerless, not given clear direction and having no SMT meetings, we were just a group of people'.

Naturally, educators took advantage of this situation and of the principal. Educators regularly stayed away from work and were generally doing as they pleased. However, there were good relationships amongst the educators themselves. Another problem was that educators were performing below average, because they had a general lack of qualifications in the subjects that they had to teach. One research participant emphasised this by stating:

'... as long as you have a 3-year diploma, even if you did not major in the subject you were teaching you were okay. Within a month of my arrival at the school I realised that no merit was used to identify Heads of Departments, performance was driven by who was who.'

(Participant)

The problems experienced by this school were deepened by the poor school management team (SMT) that had no direction, no meetings and no clear performance measures or guidelines,

TABLE 1

Learner enrollment

\begin{tabular}{|c|c|c|c|c|c|c|}
\hline Year & Grade 8 & Grade 9 & Grade 10 & Grade 11 & Grade 12 & Total \\
\hline 2000 & 470 & 338 & 500 & 363 & 252 & 1923 \\
\hline 2001 & 658 & 434 & 337 & 307 & 206 & 1942 \\
\hline 2002 & 383 & 509 & 208 & 186 & 130 & 1416 \\
\hline 2003 & 540 & 376 & 507 & 160 & 86 & 1669 \\
\hline 2004 & 637 & 332 & 374 & 310 & 94 & 1747 \\
\hline 2005 & 434 & 396 & 471 & 344 & 196 & 1841 \\
\hline 2006 & 745 & 300 & 356 & 322 & 179 & 1902 \\
\hline 2007 & 650 & 503 & 314 & 277 & 217 & 1961 \\
\hline
\end{tabular}

TABLE 2

The Grade 12 results

\begin{tabular}{|c|c|c|c|c|}
\hline Year & Number who wrote & Pass (\%) & Without *exemption (\%) & With exemption (\%) \\
\hline 1994 & 156 & 33.97 & Not provided & Not provided \\
\hline 1995 & 181 & 24.85 & 20.99 & 3.86 \\
\hline 1996 & 139 & 33.09 & 30.22 & 2.88 \\
\hline 1997 & 106 & 18.69 & 16.82 & 1.87 \\
\hline 1998 & 211 & 22.74 & 19.64 & 1.79 \\
\hline 1999 & 204 & 21.57 & 21.08 & 0.49 \\
\hline 2000 & 157 & 38.21 & 36.31 & 1.91 \\
\hline 2001 & 155 & 15.48 & 15.48 & 0.00 \\
\hline 2002 & 97 & 59.97 & 58.76 & 1.03 \\
\hline 2003 & 85 & 77.38 & 69.05 & 8.33 \\
\hline 2004 & 90 & 70.00 & 64.44 & 5.56 \\
\hline 2005 & 175 & 50.88 & 48.28 & 2.30 \\
\hline 2006 & 166 & 53.01 & 51.20 & 1.81 \\
\hline
\end{tabular}

University entrance pass. 
or any school documents to that effect. This lack of direction and performance focus in the school was evident from the poor performance of the Grade 12s. As one of the research participants said: '... subject averages ranged in the region of $30 \%$ '. The lack of management systems further led to various forms of mismanagement and financial enrichment of educators who collected school funds and admitted learners, who did not qualify and who were over age, to certain grades. One research participant provided a further description of the deteriorating situation by referring to the case of sexual harassment and the fact that the heads of the departments were involved by stating:

"The case of sexual harassment revealed low morals at the school, heads of the departments promoted immoral acts; this was a direct confirmation of mismanagement at the school.

(Participant)

When the first principal resigned, another principal was appointed, but she did not last long before she also resigned. Unfortunately, she followed the same laissez-faire policy. After she resigned, the school remained without a principal for 18 months, until the current principal was appointed in August 1997. Upon her arrival, she had the difficult task of putting management systems in place. Doing so naturally affected the educators' freedom and opportunities to enrich themselves. This created a great deal of tension and resulted in very poor personal relationships between the new principal and the staff. Owing to the lax attitude of the previous two principals who had been unable to discipline staff members; members of the SMT and educators were expecting promotion after the resignation of these two principals despite the fact that they were underperformers.

When the new principal did not oblige them as the previous ones did, 'All hell broke loose and underground movements erupted', in the words of one research participant. The research participant described this situation by using the Sotho expression, which was mostly used by educators to undermine the authority of the new principal, 'O nahana hore ke mang yena? o mang wena? - O nahana hore o sello mang?', which means, 'Who do you think you are, coming onto our turf and changing our comfort zone' (meaning emphasised to reflect the actual derogatory nature of this statement).

The unhappy educators further incited learners to write a number of memorandums to the principal, the school-governing body and the district office indicating their grievances. These frictions ended with high-court orders and restraining orders against certain educators who wanted to harm the principal. Although the department was aware of the problem, it unfortunately did absolutely nothing to address it. The total collapse of the school was the final outcome.

Eventually the principal was ousted and the school was without a principal for 14 months as from July 1998 to September 1999. During this period, there was no response from the department concerning this matter. The department in fact did not respond until the situation at school became so bad that it was exposed on a South African Broadcasting Commission (SABC) Special Assignment programme. It was only after the broadcasting of this particular episode, that the department (i.e. district office) did something about it. The principal was called back to work, but she was not taken back to the school. She worked at the district office and for all practical purposes the school remained without a principal until the end of 1999. During this time the district office sent one of the district officials to act as an administrator until the end of the year.

\section{Learning new ways through Education Action Zones involvement}

The EAZ Programme was formed and was preparing to start functioning in January 2000. This school, amongst others, was allocated to the programme because it had obtained less than $20 \%$ for its Grade 12 results. This meant that the entire province and country knew that they were dysfunctional (names of all schools who obtained less than $20 \%$ were published in The Star, a national newspaper). The EAZ Programme received widespread publicity at its inception and the schools involved in it lost their dignity and the respect of the community.

Despite the negative publicity of the schools classified as dysfunctional and the unhappiness of the teachers who were involved, the assistance of the EAZ Programme workers in general helped the non-performing schools to shape up and improve their pass rate for matriculants. The school under investigation was no exception seeing as EAZ involvement improved the school in all aspects of its functionality. This was done by implementing the following measures and changes:

- Admission of learners who were too old to qualify for certain grades was stopped.

- Involvement of all stakeholders, especially parents, was encouraged in every possible way.

- Team-building and conflict-resolution workshops were organised by the EAZ Programme.

- Clear performance measurements and guidance were presented.

- The school was well resourced.

These efforts showed immediate results, with pass and exemption rates indicating a dramatic turnaround in 2000 and a sharp upward movement in subsequent years. These gains in school management, governance and most visibly and qualitatively Grade 12 results continued until 2003. During these years of excellent performance, learners were fewer and individual attention was possible. There were three or four classes of Grade 12s, with about 34 learners in each one.

The participants voiced the following positive feedback regarding the EAZ involvement in the school:

'The EAZ resourced our school in many ways, they did renovations, gave us textbooks, conducted workshops for all staff members in areas such as finances and computer software, they ensured that all monitoring systems were in place and thus helped with keeping educators on their toes.'

(Participant)

Another participant confirmed this by stating that:

'Through the help of the EAZ we managed to form a team working towards a common goal; they gave us incentives and held continuous meetings with parents, school governing bodies and learners.

(Participant)

\section{Implementation of new ways by the school}

Various initiatives were taken by the school; the following are remarks made by various research participants:

- 'We started inviting people like pastors to give talks to our learners on a weekly basis at the school assembly.

- 'As a school management team we started analyzing results on a quarterly basis, motivated learners who were not doing well and gave guidance to subject educators on how to improve their subject average. We arranged common tests with adjacent performing schools; educators from these schools were setting examination papers on critical subjects (Mathematics, Physical Science, Accounting etc) for Grade 12s.'

The success of this collaborative approach is confirmed by Ainscow, Muijs and West (2006) when acknowledging that under the right circumstances school-to-school collaboration can be a powerful means of strengthening the capacity of schools to address complex and challenging circumstances, by widening student-learning opportunities and helping to address the needs of vulnerable groups of learners.

According to the participants, the entire school was now a team that was working towards attainment of a common goal, namely 
learner achievement. Highly-focused meetings of the SMT were held on a weekly basis. The agenda focused on remedial work, tracking of syllabus completion, closing of identified loopholes and interrogation of the head of the department by the principal and deputy principals and giving them advice on how to improve the general management and performance of their departments.

Incentives were given to learners and educators who were walking the extra mile in achieving the school's vision and mission. The school developed all the needed school policies for issues concerning admission, language, safety and HIV/ Aids. Due to proper admission policies that required proper documentation from learners such as previous school reports, birth certificates, etc led to learner numbers dropping. Learners of good quality were being admitted. The involvement of parents and the general community increased remarkably.

It was clear that the external pressure that was placed on the educators resulted in them working together towards school improvement. One participant stated, 'We had to do everything in our power to be removed from the EAZ category'.

All these efforts by the SMT were directly responding to one of the objectives of the study, namely, the intention to explore the influence of external pressures in comparison with internal motivation in an effort to sustain performance and positive change. In other words, to these educators, internal motivation was a driving force for their high performance although the external pressure was used as a vehicle to achieve this. Hollins, Gunter and Thomson (2006) support this when they state that effective improvement in Kingswood (the school they were studying) was less about the implementation of external reform agendas and was more about working for educational goals regarding learners and learning.

As agreed, the EAZ intervention process ended when the targeted schools reached the desired performance standard and a Senior Certificate pass rate of $60 \%$. It gradually withdrew from the first-cycle schools having registered visible and desired educational signs of performance. These schools, including the one under investigation, were handed back to the district for total control, support and monitoring of all aspects of school development.

\section{Falling back into old ways}

Findings by Fleisch (2006) indicate that a small but significant group of schools were slipping back to the EAZ Programme after the third year. Unfortunately, at the end of 2004, when most EAZ fieldworkers were withdrawn from the schools, a number of EAZ schools, after having graduated successfully from the EAZ category fell back. The school under investigation was one of them. New performance standards indicating the pass rate for Grade 12 students in a school as $60 \%$ were set by the department in December 2006. This resulted in the classification of the majority of the 71 schools identified as underperforming schools to once again experience the shame of being branded as such. This new benchmark upset educators in the school, as one participant said: 'Many educators are tired of the old school, we do not want to go back to the EAZ'.

The aim of this study was to determine the reasons for the failure of the EAZ Programme in a school which managed to increase the passing rate of Grade 12 students and to perform well. Being a qualitative study and thus being flexible and making provision for new discoveries, it was soon realised after embarking on the research process that the researcher's preconceived ideas that the positive changes in the school could not be sustained owing to of the laziness of educators and a lack of commitment and leadership, were unfounded. This became especially clear during the third round of interviewing when the findings were verified. In fact, by being able to observe the principal and the way she was operating, she appeared to be a well-organised, committed person who knew what she was doing. The school records in her office were well kept. She clearly knew what was expected of her and what she in turn expected from the SMT members. The management team thus has good direction, clear performance measures and guidelines to follow. Therefore, the situation regarding the management of the school was very similar to that when the EAZ was involved.

By observing the Grade 12 educators (July 2007) and discussing the recovery plan for Grade 12s, it became clear that despite the problems that the school was experiencing at the time, they were a positive group of committed educators who were even prepared to teach on Saturdays.

After having studied the views of the research participant the researcher realised that the reasons for not being able to sustain the positive changes brought about by the EAZ mostly concerned decisions and changes made in the education system as a whole and more specifically the introduction of the new curriculum. The new problems that the educators had to face were therefore mostly beyond their control, as one participan stated: 'When the EAZ pulled out there were many curriculum changes, and educators were very uncomfortable'. The school never had strong educators in Further Education and Training (FET). The few educators that were there were over-stretched due to the many classes necessary for Grade 12 . The textbooks for Grades 10-12 in the new National Curriculum Statement were intimidating to educators. One educator, after viewing these textbooks, asked whether there were no other easier reference books. In general, educators were minimally qualified to teach subjects allocated to them and this became worse as new subjects such as Mathematics Literacy, as well as new themes in certain subjects like Evolution in Biology (Life Sciences) were being introduced in the FET phase.

This lack of control led to a growing feeling of helplessness and doubt in their ability to deal with the situation. The result was a resurfacing of old internal 'izivunguvungu' or 'moya wa ho senya' (meaning 'cyclone' or 'destabilising spirit'). Teachers' confidence was dwindling and there was an inability to prepare lessons according to the standards of the new curriculum. More and more squabbles started to take place when doing subject allocation because teachers were not willing to teach in the FET phase. One research participant had this to say: 'Titshere walla o mo e ntse ing?' (which means 'Teachers are crying. What are you doing to them?'). This situation gave rise to a high rate of absenteeism of educators claiming to be ill.

Naturally, the learners became frustrated, demotivated and unhappy with the situation. This unhappiness gave rise to an uncooperative, arrogant attitude and aggressive behaviour. The limited resources such as chairs, toilets and textbooks worsened this situation. On top of this, corporal punishment was abolished and alternative ways of punishment given by the department were not effective, thus making it almost impossible to control learners, especially those who were aggressive or using drugs. This negative situation impacted badly on the parents who, because of all this, became less involved with the school

\section{The feeling amongst research participants was that:}

'... if the EAZ were still here the introduction of the new curriculum in the FET phase would be very easy, because they could supplement the training done by the department by conducting more workshops on how to implement the new curriculum.

(Participant)

This statement, however, cast doubts on the issue whether the EAZ could have succeeded in helping the school as it was not their task to assist with the introduction of the new curriculum. At best, EAZ officials could have identified the difficulties experienced with the new curriculum at an earlier stage.

As the perceptions of educators at grass-roots level were analysed in an effort to outline guidelines towards the development of a 
policy aimed at sustaining secondary school performance, two overarching themes gave rise to poor school performance and the inability of the school to sustain its high performance. These were the following:

\section{Theme 1}

There were serious signs of instability in the school before the intervention programme started. The following type of problems caused this:

- a serious lack of resources

- poor leadership

- lack of commitment of educators

- insufficient knowledge of subject content

- poor relationships due to changes brought about by the new principal

- poor communication between the school and the Education Department.

\section{Theme 2:}

The following difficulties were experienced with the new curriculum:

- Contrary to the researcher's belief and the perceptions of EAZ team members, the lack of sustainability of the intervention programme in the school was not caused by lack of accountability of the management team or a lack of commitment of teachers and the inability of the principal to manage the school.

- The main reason for the difficulties was related to the introduction of the new curriculum with special emphasis on the FET phase for Grades 10-12 without any support or guidance from the district.

- Another important reason for the existence of difficulties was the increase in enrollment figures with no provision for extra resources.

\section{DISCUSSION}

This study was aimed at gaining an understanding of the reasons why the school in question was unable to sustain the high performance reached during the implementation of the EAZ Programme.

According to Fleisch and Christie (2004, p. 100), research undertaken in dysfunctional schools in Gauteng during the period of 1994-1995 identified the following four sets of problems:

- poor physical and social facilities that had an ongoing negative impact on teaching and learning

- serious organisational problems, including weak and unaccountable leadership and administrative dysfunctioning

- poor communication and inadequate disciplinary and grievance procedures

- poor relationships with surrounding communities, as well as poor communication between the schools and the Education Department.

Some of these findings, especially poor leadership and lack of direction and performance focus before the implementation of the EAZ Programme, point directly to the causes of instability in the school under study. Various literature studies in education management over the last few years have consistently emphasised the importance of the school leadership, particularly that of the principal, in ensuring successful functioning of the school. Thus, for any school to function properly and sustain the inputs made by the department, for example, the EAZ Programme, strong visionary leadership is needed that will enhance the performance of its employees and that will improve the production of the organisation in general.

It is unfortunate that the training of educators in high-risk subjects such as Mathematics and Physical Science was never done by the EAZ, although it was one of its mandates. As (Fleisch, 2006) indicates, the EAZ was designed as a comprehensive systemic initiative, which would include monitoring schools and providing support and training to principals, teachers and pupils. However, in reality, focusing largely on accountability measures (Fleisch, 2006), the programme did not fully meet its systemic intentions. The reasons were that the behavioural problems of the schools involved in the programme superseded their curricular problems.

Other reasons relating to National Curriculum Statement (NCS) training mentioned by interviewees include the lack of foundation in the lower grades, that is, Grades 1-9. The recent NCS research findings by the Department of Education (2007) reveal that the implementation of the NCS in the Foundation Phase was not smooth and that the continuous review thereof did not take place.

Fleisch (2006) supports this argument by stating that some scholars have suggested that only coherent and systemic policies from the centre could drive large-scale reform. He states that these educators argue that strong instructional guidance driven through aligned curriculum framework, teacher development and assessment and learning materials could lead to substantial and sustained improvement in schools.

Added to these challenges faced by the school is the issue of forced over-enrollment of learners. This added to the frustrations of educators and managers because it directly impacted on disciplining learners who were fighting for limited resources such as chairs, toilets, etc. It is worth noting that no matter how much planning regarding admissions the Provincial Department is doing during a current year, it is a known fact that township parents will still bring children for admission in January the following year when teaching and learning should start. Even the high migration to the Gauteng Province adds to the admission challenge. Thus, schools are forced to admit huge numbers of extra learners for whom no provision was made. This causes insufficient resources that lead to many other problems as indicated earlier on. This puts a further strain on the educators who are already unhappy and on resources that are already inadequate.

Payne (2005) points to the fact that racial and class tensions, coupled with resource scarcity and a difficult environment, hindered the implementation of a school-reform project.

It is not the termination of the EAZ Programme that caused this outcome. Once again, at best, it could be reasoned that the EAZ team members could have discovered the problems with the curriculum at an earlier stage. This was clear from the following statement of one of the research participants:

'The introduction of the new curriculum was found to be the most crucial reason for the non-sustainability of the EAZ Programme. As indicated the school was never strong academically and could therefore not cope with the expectations of the department to employ a different curriculum with new subject content, for which teachers were not trained.'

(Participant)

These findings indicate the serious problems the country has in terms of teacher development and training. The situation is worse in the FET phase seeing as there is new content in certain subjects of the new curriculum. This directly leads to teacher confidence dwindling and to their poor self-esteem and gives rise to unnecessary behavioural problems of educators, for example, a high rate of absenteeism, absconding from classes, sickness, et cetera. All these problems are only symptoms of the deeper underlying problem, which reflects the lack of confidence of the teachers to perform in front of learners due to their insufficient knowledge of subject content, poor assessment and teaching strategies. 


\section{CONCLUSION}

The aim of the study was to determine the reasons for the inability of the school to sustain school improvement. Contrary to the perception of EAZ members and scholars in the education field many of the reasons for the school's failure were not found in expected circumstances such as a lack of leadership and motivation of educators who were responsible for the failure of the school prior to the implementation of the EAZ Programme. In fact the findings showed that despite the difficult circumstances this school that was, prior to EAZ intervention, branded as highly dysfunctional still managed to retain most of the systems put in place by the EAZ Programme.

The overarching reasons for the lack of sustainable performance of the school point to the entire education system rather than to the school per se. Therefore the assumptions made that the school itself was unable to sustain its performance and the positive change when the EAZ Programme terminated were unfounded.

The results of the research clearly indicate how complex education problems are in South Africa and perhaps in the entire world. It also reflects the importance of qualitative research in the education sector, in that it reveals realities of the social phenomenon as witnessed by those involved in it on a daily basis, as opposed to external people who do not have a deeper understanding of social processes within a certain social institution.

Taylor (2003) states that strategies for change require focusing on both the school and the Department of Education. Reeves, Forde, O'Brien, Smith and Tomlinson (2002) also confirm this by indicating that the need to engage with teachers in bringing about reform will be unavoidable in the end. Schools need to establish for themselves exactly what they wish to achieve and they need to select and modify procedures and structures accordingly. They further state that it is the learning of teachers in action that makes a difference to their behaviour and therefore the task of performance management is to explore the ways in which such learning can be supported in school and how external provision and networking with other institutions can best enhance that support.

That is why the grass-roots guidelines of the participants are so important. Such guidelines that are based on the experience of the educators themselves, could help the Department of Education to both understand why successes in schools cannot be sustained, as well as prevent the failure of future intervention programmes. More importantly, these recommendations point to the fact that educators as practitioners show a need to work closer together with researchers, believing that this will enable them to achieve and sustain the successes that have been reached.

\section{Limitations of the study}

A notable limitation is that the present study is at best an explorative one. Because the research employed a case-study design which involved only a small sample, the knowledge gained from the research findings could not be generalised to other research settings. Furthermore the overarching reasons for the lack of sustainable performance of the school pointed to the fact that a new curriculum was implemented without providing the necessary training and support to educators and not because the school was unable to sustain the improvements made under the guidance of the EAZ. In fact, the unexpected finding was that the implementation of the new curriculum with its accompanying higher standards in a system where many educators were already not sufficiently trained to perform in the old system was to blame for the under-achievement of learners at the school. Coupled with this was the unexpected higher enrollment figure of children due to a high influx of people into Gauteng and the resulting lack of resources.

Although these were not limitations of the study, it points to the fact that urgent investigation into the implementation of the new curriculum and the influx of learners into areas where schools were already under-resourced needed to be undertaken.

\section{Recommendations}

The existing forums of the Gauteng Department of Education could be used to advance research within the department. Curriculum and institutional support actions are core features of the Department of Education. Those involved in these forums should therefore be the drivers behind capacity building in planning, assessment and reporting and the enhancement of the teachers' confidence and their self-esteem and capabilities to teach.

Research questions and findings could be addressed in these forums. It is suggested that every meeting should have a standing agenda item on research findings or research that needs to be undertaken. An existing research unit that is based at the provincial head offices of the department could also assist in this manner. Coupled with this can be the inclusion of educators in these research projects by means of an action-research framework. This will not only show us through reflection of what is happening in the classroom in terms of teaching and learning, but will also develop the educator's research skills which are so needed in the underperforming schools.

Reeves et al. (2002) acknowledge that little is known about the impact of curriculum development and support on practice or the operations of particular approaches such as the use of critical reflection and action research. They further argue that teachers need opportunities to engage in understanding the implications of these changes and exploring the means of responding effectively to them by means of a consistent, persistent and progressive action-orientated approach to professional development. Hollins, Gunter and Thomson (2006, p. 148) echo this by indicating that claims about improvement for the effective school need to be part of a close-to-practice strategy by involving practitioners and researchers who are working together to make use of the best available knowledge to develop strategies that are more effective. Such a strategy could help even experienced practitioners to improve their performance.

In the light of these results it is imperative that the current Directorate for Interventions and Governance should spearhead the documentation of all interventions, both those previously done (if possible) as well as the current programmes implemented by the department. Again, this may be done through the current Research Unit at Head Office. As indicated by Mbeje (2007) in the past few years, a substantial amount of resources have been allocated to various school- and districtimprovement programmes. Some of these interventions were effective, but they were not sufficiently documented to ensure that they could be sustained and replicated. According to Mbeje (2007) other interventions were not effective, but very rarely were shortcomings openly and honestly acknowledged and researched.

\section{Participants' suggestions for sustaining performance}

The participants acknowledged the following important prerequisites for the success of any intervention programme aimed at improving school performance:

- The strategy for improvement should be based on teacher learning within the context of the school.

- All teachers must be involved in the management and running of the school according to set guidelines and policies.

- Teachers, learners, parents and other stakeholders such as community members must be involved in the school and must take responsibility for their school's functioning.

\footnotetext{
Forums such as The Curriculum and Governance Forum for all Chief Education Specialists who are heading curriculum development and support, as well as those heading the institutional development support in our schools and the Curriculum heading the institutional development support in our schools and the Curriculum Information For
} 
More specifically, the following guidelines that are aimed at sustaining an intervention programme were proposed by the participants:

- A similar EAZ intervention team is to be set up, specifically to focus on providing guidance for the implementation of the curriculum.

- Intensified teacher and/or facilitator development is needed before introducing a new curriculum, followed by continuous quality in-service training undertaken by experienced nationally-appointed tutors.

- Effective cooperation must be created at all levels of the department, especially at district and sub-directorate level.

- Plans to work together with neighbouring schools, both primary and secondary, using and developing common work schedules, lesson planning and performing common assessment tasks must be developed and implemented.

- Over-enrolment must be avoided and proper resources for schools must be provided.

- A social worker, policeman and psychologist must be available to cooperate when needed.

- Education service delivery at all levels, that is, school, district and provincial must be intensely monitored.

- Team spirit must be improved and strong relationships built through workshops to enhance the motivation and selfimage of all staff members in a school.

- The National Department should provide a friendly detailed and clear instrument that defines and measures a functional school.

- External evaluation should be undertaken annually at all levels, that is, school, district and provincial.

\section{REFERENCES}

Ainscow, M., Muijs, D., \& West, M. 2006. Collaboration as a strategy for improving schools in challenging circumstances. Improving Schools, 9(3), pp. 192-202.

Babbie, E. 1983. The Practice of social research (Third Edition), Belmont, CA: Wadsworth Publishing Co.

Bipath, K. 2002. Differentiating between functional and dysfunctional schools. Unpublished master's dissertation, Johannesburg: Rand Afrikaans University.
Department of Education 2007. National curriculum statement assessment guidelines for general education and training (Intermediate and Senior Phases) Technology http://www. education.gov.za/Curriculum/GET/doc/ATechnology.pdf for the first 71 EAZ schools (2000-2002).

Fleisch, B. 2002. Tight control models for improvement. A case study of the Education Action Zones. Paper presented at the Third Educationally Speaking conference. 23-25 May, Buffelspoort, Warmbath.

Fleisch, B. 2006. Bureaucratic accountability in the Education Action Zones of South Africa. South African Journal of Education, 26(3), pp. 369-382.

Fleisch, B.D., \& Christie, P.H. 2004. Structural change, leadership and school effectiveness/improvement: Perspectives from South Africa. Discourse: Studies in the Cultural Politics of Education, 25(1), pp. 95-112.

Hollins, K., Gunter, H.M., \& Thomson, P. 2006. Living improvement: A case study of a secondary school in England. SAGE, 9(2), pp.141-152.

Little, M. E., \& Houston, D. 2003. Research into practice through professional development. Remedial and Special Education, 24(2), pp.75-87.

Marshall, C., \& Rossman, G. 1995. Designing qualitative research (Second Edition). Newbury Park: Sage.

Mason, J. 1996. Qualitative researching. Thousand Oaks: Sage.

Maxwell, J.A. 2005. Qualitative research design: an interactive approach. (2nd ed). Thousand Oaks, CA: Sage Publications.

Mbeje, Z. 2007. Leadership and governance. Paper presented at the Gauteng Department of Education Curriculum and Governance Cluster Conference, 20 July, Benoni, Johannesburg.

Payne, R.K. 2005. A framework for understanding poverty. Fourth Revised Edition. Highlands: Aha! Process.

Reeves, J., Forde, C., O’Brien, J., Smith, P., \& Tomlinson, H. 2002. Performance in education improving practice. Leicester: Paul Chapman Publishing.

Ritchie, J., \& Lewis, J. 2003. Qualitative research practice: a guide for social science students and researchers. Thousand Oaks: SAGE.

Schurink, W.J. 2004. Lecture ten: Data analysis. Unpublished training course. Johannesburg: Rand Afrikaans University.

Schwandt, T.A. 2007. The Sage dictionary of qualitative inquiry. Thousand Oaks: Sage.

Taylor, J. 2003. Institutional diversity in UK higher education: Policy and outcomes since the end of the binary divide, Higher Education Quarterly, 57, 3, pp.266-193. 